P0178

TUNNEL INTERIOR LIGHTING FOR SAFETY IN TWO-WAY TRAFFIC

\author{
Kishimoto Satoru et al.
}

DOI 10.25039/x46.2019.PO178

from

CIE x046:2019

Proceedings

of the

29th CIE SESSION

Washington D.C., USA, June 14 - 22, 2019

(DOI 10.25039/x46.2019)

The paper has been presented at the 29th CIE Session, Washington D.C., USA, June 14-22, 2019. It has not been peer-reviewed by CIE.

(C) CIE 2019

All rights reserved. Unless otherwise specified, no part of this publication may be reproduced or utilized in any form or by any means, electronic or mechanical, including photocopying and microfilm, without permission in writing from CIE Central Bureau at the address below. Any mention of organizations or products does not imply endorsement by the CIE.

This paper is made available open access for individual use. However, in all other cases all rights are reserved unless explicit permission is sought from and given by the CIE.

CIE Central Bureau

Babenbergerstrasse 9

A-1010 Vienna

Austria

Tel.: +4317143187

e-mail: ciecb@cie.co.at

www.cie.co.at 


\title{
TUNNEL INTERIOR LIGHTING FOR SAFETY IN TWO-WAY TRAFFIC
}

\author{
Kishimoto, S. ${ }^{1}$, Ito, H. ${ }^{1}$, Abe, S. ${ }^{2}$, Soma, R. ${ }^{3}$ \\ ${ }_{1}^{1}$ Panasonic Corporation, Tokyo, JAPAN, \\ 2 Central Nippon Expressway Co. Ltd., Tokyo, JAPAN, \\ ${ }^{3}$ Central Nippon Highway Engineering Tokyo Co. Ltd., Tokyo, JAPAN, \\ kishimoto.s@jp.panasonic.com
}

DOI 10.25039/x46.2019.PO178

\begin{abstract}
This paper proposes a tunnel interior lighting system for safety in two-way traffic on highways. The target tunnel had longitudinal slopes with sag (vertical curve) of $4 \%$ at the maximum, which had been the concern leading to a rear-end collision in speed degradation of a preceding car and a serious front collision in the two-way traffic. Since 2010 in Japan, many tunnel lighting systems had been replaced by LED luminaires, which in some cases resulted in uneven luminance distribution of the road surface and discomfort glare even in the tunnels considered the CIE recommended criteria including uniformity of road surface luminance and a glare restriction (CIE 2004). Considering these condition, therefore we reviewed lighting system requirements in the tunnel with two-way traffic.
\end{abstract}

Keywords: Tunnel interior lighting, Uniformity of road luminance, Discomfort glare

\section{Introduction}

In order to secure the safety for the motorway tunnel with two-way traffic, we conducted reviews for the vertical illuminance on the rear end of the preceding car or the front of the opposite car to improve the visibility of these cars and also for the issue in the design value to reduce uneven luminance distribution of the road surface and a discomfort glare in tunnel interior lighting due to replacement to LED lighting. For on-site installed lighting system based on above obtained lighting designed value, discussion for the lighting properties measurement and the visual environment are shown here.

\section{Designed value for tunnel interior lighting}

\subsection{Visibility of driving cars}

If a tunnel with large longitudinal slope also has "sag (vertical curve)" of which transition from downhill to uphill, a following distance may decrease due to the speed variation of you and a car driving in front leading to congestion or a rear-end collision. To see enough the behavior of both cars driving in front and passing through, it is required to ensure visibility. Driver's visibility depends on the vertical illuminance on the rear of a preceding car or on the front of an oncoming car and these vertical illuminance values tend to be proportional to their following distance. (Ito et al, 2015) Then it was decided that system with a vertical illuminance of 35 Ix (visibility of that is one level higher than a symmetric lighting system with an average vertical illuminance $20 \mathrm{Ix}$ ) should be given. Figure 1 shows CG images for visibility in two lighting systems. 


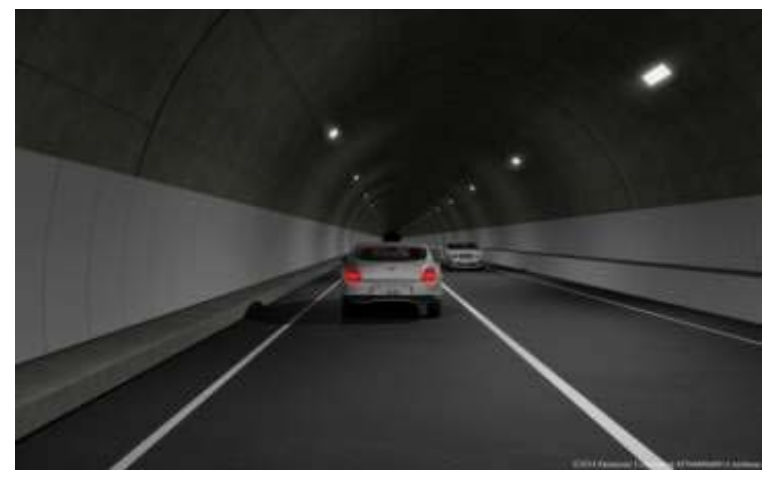

(a) Symmetric lighting system

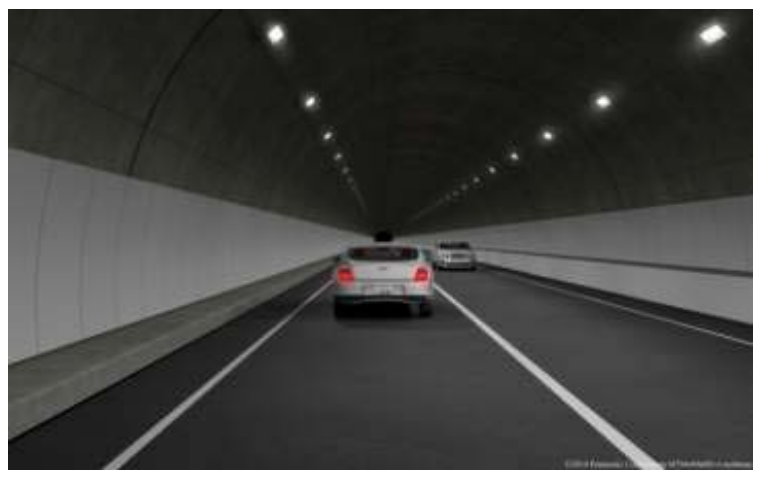

(b) Improved lighting system

Figure 1 - CG images of visibility of cars

\subsection{Uniformity of road luminance}

In recent years, although the LED has become to be used as tunnel light sources, even in the design which ensure required overall uniformity of road luminance Uo and longitudinal uniformity of road luminance $U I$, uneven luminance distribution of the road surface occurs sometimes compromising driving comfortability. With the technological progress in road surface pavement, it is assumed that reason is the effect from reflection property of $C$ classification in CIE recommendation which do not derive distribution of road surface luminance properly.

As the drainage pavement generally adopted in Japan expressway has a higher specular than a dense asphalt pavement, measured values for the road surface luminance on-site and calculated values for the distribution of road surface luminance using the reflection property of $W$ type classification were compared. The result shows a high correlation between measurements and $W 2$ classification.

In distribution of road surface luminance in the existing tunnel lighting system using fluorescent lamp and low pressure sodium lamp, uneven luminance distribution of the road surface tended to be found in road longitudinal direction, while in LED lighting it was seen in road transverse direction. For that reason, uniformity of road luminance in transverse direction became to be defined. On-site experiment showed that value of transverse uniformity of road luminance Uw more than 0,6 may reduce discomfort in driving visibility. Figure2 shows the distribution of road luminance in the transverse uniformity of road luminance 0,50 to 0,65 .

\subsection{Discomfort glare}

Same as above uniformity of road luminance, even in the tunnel which is less than TI value of CIE recommendation, the discomfort glare tended to be unsuppressed due to the replacement of LED in tunnel lighting. On-site experiment has shown that the discomfort glare was correlated with equivalent veiling luminance. Later discussion have proposed evaluation index of the discomfort glare using the equivalent veiling luminance and road surface luminance as explanatory variable (Hirakawa et al, 2019), however, in this paper, to reduce the discomfort glare, the equivalent veiling luminance is not more than $0,32 \mathrm{~cd} / \mathrm{m}^{2}$. 


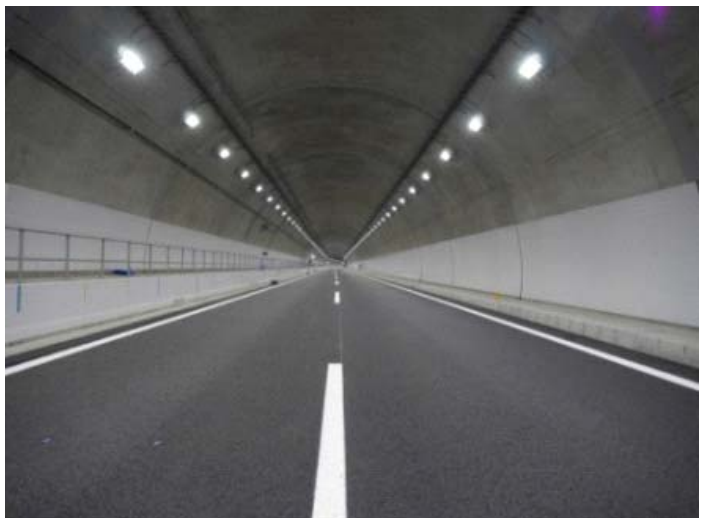

(a) $U w=0,65$

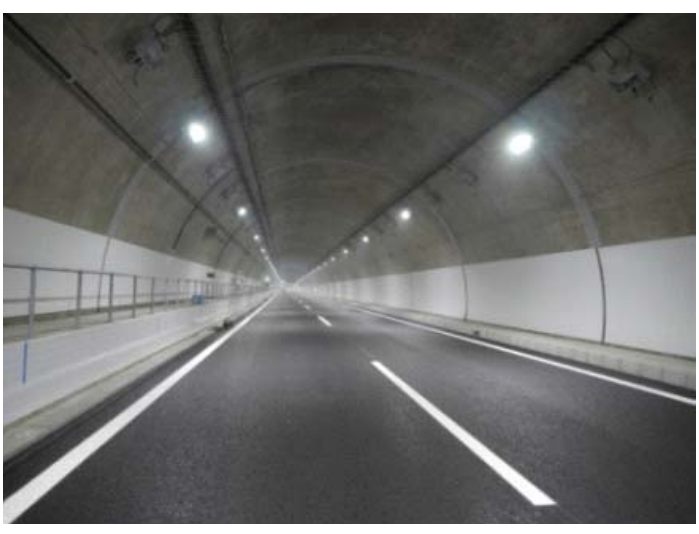

(c) $U w=0,50$

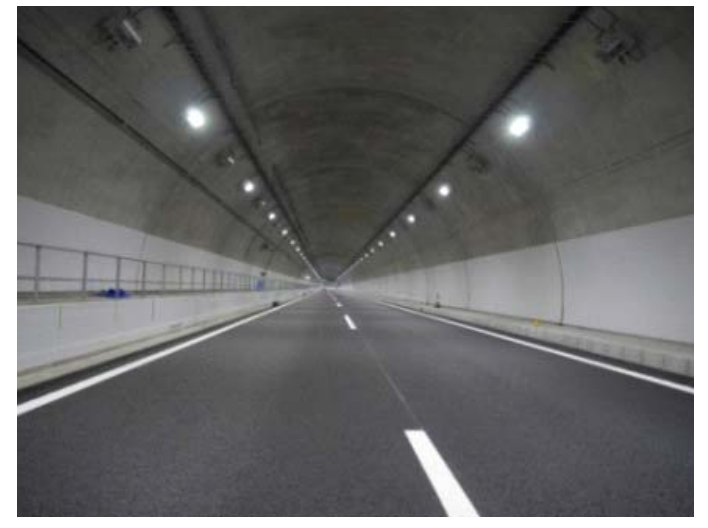

(b) $U w=0,60$

Figure 2 - Road luminance distribution of different uniformity in the tunnel transverse direction

\section{Observations}

\subsection{Lighting installation}

Using lighting design conditions of Table 1, interior lighting systems for Hachinoshiri Tunnel in Chubu Odan Expressway had been installed. Luminaries providing luminous flux $5600 \mathrm{Im}$ were arranged with opposite arrangement, mounting height of $4,73 \mathrm{~m}$ and spacing of $8,7 \mathrm{~m}$.

\section{Table 1 - Lighting design conditions}

\begin{tabular}{|l|c|}
\hline Design speed & $70 \mathrm{~km} / \mathrm{h}$ \\
\hline Road surface luminance & $3,2 \mathrm{~cd} / \mathrm{m}^{2}$ \\
\hline Overall uniformity of road luminance $U o$ & 0,4 \\
\hline Longitudinal uniformity of road luminance $U l$ & 0,6 \\
\hline Vertical illuminance & $34 \mathrm{Ix}$ \\
\hline Transverse uniformity of road luminance $U w$ & 0,6 \\
\hline Equivalent veiling luminance & $0,3 \mathrm{~cd} / \mathrm{m}^{2}$ \\
\hline Maintenance factor & 0,6 \\
\hline
\end{tabular}

\subsection{Observation procedures}

As observers, men and women of lighting engineers at the age of 23 to 55 performed the following subjective evaluation. 
(1) Evaluating visibility of cars

The observers seated in a car stopped on the road subjectively evaluated visibility of silver coloured cars placed $70 \mathrm{~m}$ ahead on the same lane or on the opposite lane using 5 scale rating (5: Good, 4: Fairly good, 3: Just admissible, 2: Fairly poor, 1: Poor).

(2) Evaluating uniformity of road luminance

After the evaluation of the visibility for cars located ahead of observers as above, the observers also evaluated the uniformity of road luminance with 5 scale rating (5: Good, 4: Fairly good, 3: Just admissible, 2: Fairly poor, 1: Poor).

(3) Evaluating discomfort glare

Observers sitting in the car stopped on the road just under a lighting system subjectively evaluated the discomfort glare at the field of view in driving direction by 9 scale rating (9: Unnoticeable, 7: Satisfactory, 5: Just acceptable, 3: Just acceptable, 1: Unbearable) (De Boer et al, 1959).

\section{Results of observations}

\subsection{Visibility of cars}

As all observer evaluation of visibility of cars were not less than "3: Just admissible" and average rating was 3,5 and over, it was shown to secure the required visibility of car driving ahead and from opposite direction. Figure 3 shows the cars of which visibility were assessed.

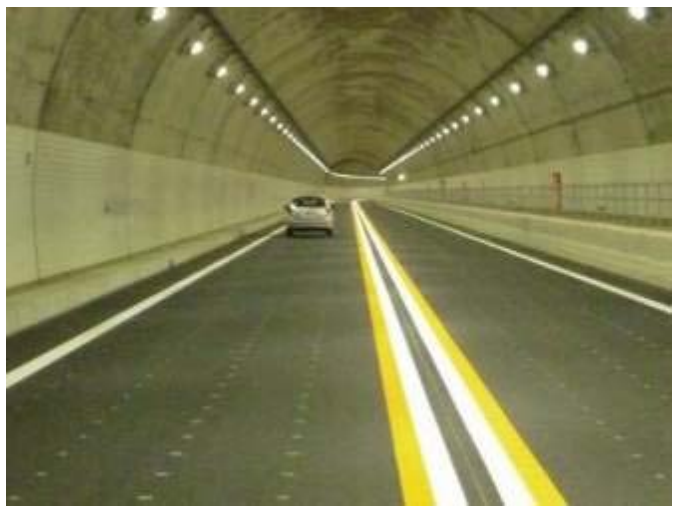

(a) Car placed on the same lane

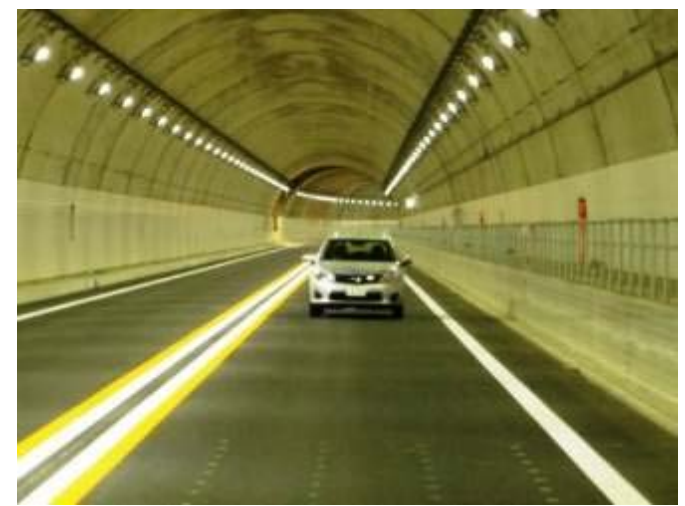

(b) Car placed on the opposite lane

Figure 3 - Observation for the visibility of the cars

\subsection{Uniformity of road luminance}

Although 3 out of 11 observers evaluated here as " 2 : Fairly poor", more than $70 \%$ of all choose "3: Just admissible" or higher rating and the average was 3,5 and over. It means to secure the required uniformity of road luminance. Figure 4 shows the distribution of the road surface luminance seen from observation car.

\subsection{Discomfort glare}

All observers evaluated here more than 6 (of 9-level rating), and average of this was more than "7: Satisfactory". It means that level of discomfort glare was mitigated. 


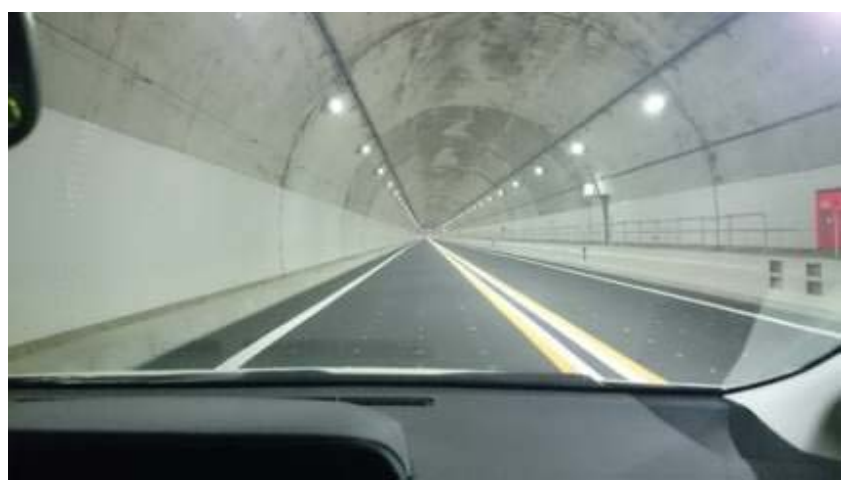

Figure 4 - Observation for uniformity of road luminance

\section{Conclusion}

Because of limited measures to avoid the risk in two-way traffic tunnels, serving lighting environment which allow driver to correctly find the cars driving in front or coming from opposite is necessary. In the design phase, using three criteria of (1) vertical illuminance, (2) transverse uniformity of road luminance, and (3) equivalent veiling luminance, as proposed in this paper to secure those requirement of those criteria, the visibility of cars in both directions were improved in 1 level (of 5-scale rating). Therefore, lighting environment that may control discomfort from uneven luminance distribution of the road surface and glare became to be given.

This review showed that pro-beam lighting systems which were considered as technically difficult in two-way tunnels before now are effective.

\section{References}

CIE 2004. CIE 88 2nd:2004. Guide for the lighting of road tunnels and underpasses. Vienna: CIE.

De BOER J. B. et al 1959. Appraisal of the quality of public lighting based on road surface luminance and glare. Proceedings for the 14th Session of CIE, 529-538.

HIRAKA, S. et al 2019. Evaluation method of discomfort glare for LED tunnel interior lighting. Proceedings for the 29th Session of the CIE.

ITO, H. et al 2015. Tunnel lighting design for energy saving by the method of high uniformity. Proceedings of the 28th Session of the CIE, 869-876. 